\title{
Impact of Homozygous C4A Deficiency on Clinical Presentation of Systemic Lupus Erythematosus
}

\author{
Ayesha Arooj Ansari ${ }^{1}$, Hamid Nawaz Tipu', Dawood Ahmad ${ }^{1}$ and Muhammad Farhan ${ }^{2}$ \\ ${ }^{1}$ Department of Immunology, Armed Forces Institute of Pathology, CMH Rawalpindi, Pakistan \\ ${ }^{2}$ Armed Force Bone Marrow Transplant Center, CMH Rawalpindi, Pakistan
}

\begin{abstract}
Objective: To investigate the association of C4A null allele (C4AQ0) with systemic lupus erythematosus (SLE) and determine the clinical presentation of SLE in relation to C4A null allele.

Study Design: Descriptive study.

Place and Duration of Study: Armed Forces Institute of Pathology (AFIP), Rawalpindi, Immunology Department, from December 2018 to December 2019.

Methodology: Patients referred to AFIP, who fulfilled American College of Rheumatology (ACR) criteria of 1997 for diagnosis of SLE were included in the study. Approval from the Institutional Ethical Review Board was taken. C4A and C4B null alleles were determined in 66 SLE patients and 40 age- and gender-matched healthy controls by polymerase chain reaction (PCR) using sequence-specific primers (PCR-SSP). Various clinical features and laboratory findings in the SLE patients were analysed in relation with C4A null allele.

Results: The mean age of the study population was $30.56 \pm 10.08$ years. C4A null allele was detected in 7 (10.6\%) patients; whereas, C4B null allele was detected in only two (3\%) patients. SLE patients with C4A null allele had increased incidence of arthritis (100\%) and renal damage (85.7\%); compared to those with normal C4A allele, 57.6\% and 32\%, respectively. Fisher's Exact test revealed strong association of C4A null allele with arthritis and renal damage, $(p=0.039$ and 0.01 , respectively).

Conclusion: Homozygous absence of C4A alleles was encountered in $10.6 \%$ of Pakistani patients of SLE and is closely related with clinical features of arthritis and renal damage. Knowledge of C4A null allele in SLE patients at diagnosis can predict disease course.
\end{abstract}

Key Words: SLE, C4A null alleles, C4AQ0, Homozygous C4A deficiency.

How to cite this article: Ansari AA, Tipu HN, Ahmad D, Farhan M. Impact of Homozygous C4A Deficiency on Clinical Presentation of Systemic Lupus Erythematosus. J Coll Physicians Surg Pak 2020; 30(08):790-795.

\section{INTRODUCTION}

SLE is a heterogeneous autoimmune disease with a wide spectrum of clinical and serological manifestations resulting from an interaction of genetic, environmental and hormonal factors. ${ }^{1,2}$ It is a systemic autoimmune disorder characterised by multiple auto-antibodies against cell nuclear constituents DNA - histones and ribonucleoprotein. ${ }^{2}$ Its incidence ranges from 1 to 10 per 10,000 person-year and prevalence from 20 to 70 per $100,000 .{ }^{3}$ Reported prevalence of SLE in South Asia is 3.1 per $100,000 .{ }^{4}$ It affects women of child-bearing age with the highest incidence in African-Americans. ${ }^{4}$

Correspondence to: Dr. Ayesha Arooj Ansari, Department of Immunology, Armed Forces Institute of Pathology, CMH Rawalpindi, Pakistan

E-mail: ash.arooj88@gmail.com

Received: April 13, 2020; Revised: August 03, 2020;

Accepted: August 13, 2020

DOI: https://doi.org/10.29271/jcpsp.2020.08.790
SLE shows great heterogeneity in disease pathology, commonly involving skin, articular joints and kidneys. ${ }^{5}$ Constitutional symptoms like fatigue, fever and weight loss occur in most patients. Arthritis is symmetrical, poly-articular, and non-erosive occurs in 65 to $70 \%$ cases. Renal involvement occurs in about $50 \%$ cases and is the main cause of morbidity and mortality. ${ }^{5-7}$

Many complement component deficiencies, both inherited and acquired, are associated with SLE. One of the most common genetic associations in SLE is deficiency of components of classical pathway $\mathrm{C} 1, \mathrm{C} 4$ and $\mathrm{C}^{8}$. However, the strength and severity of SLE disease is highest for homozygous $\mathrm{Clq}$, relative to homozygous $\mathrm{C} 4$ and $\mathrm{C} 2$ deficiency. $\mathrm{C} 4$ genes are present in class III region of MHC on chromosome 6 p21.3. ${ }^{8} \mathrm{C} 4$ has two highly polymorphic isotypes, $C 4 A$ and $C 4 B$ with at least 13 allelic forms for C4A and 22 alleles for C4B including C4AQ*0 and C4BQ*0; the null alleles that have no protein expression. ${ }^{9,10}$ Null allele is associated with SLE and is present in $5-14 \%$ of patients with SLE and 1-6\% of general population. ${ }^{10-12} \mathrm{C} 4 \mathrm{~A}$ has higher affinity for immunoglobulins and, therefore, more efficient than C4B. It also functions to regulate and maintain B-cell 
tolerance. ${ }^{13}$ Defects in C4A cause decreased clearance of autoantibodies, resulting in SLE and other immune complex mediated diseases. C4A plays important role in opsonisation, solubilisation and clearance of immune complex and C4B in mediating immune hemolysis. ${ }^{14}$

Standard immunologic laboratory tests for diagnosing SLE include detecting antinuclear antibodies (ANA), anti-double stranded DNA antibodies (anti-dsDNA), extractable nuclear antigen antibodies (anti-ENA) and complement proteins $\mathrm{C} 3$ and C4. Proteins C3 and C4 play a pivotal role in pathogenesis of immune complex mediated damage. ${ }^{5} \mathrm{C} 4 \mathrm{~A}$ and $\mathrm{C} 4 \mathrm{~B}$ are tested by their differences in electrophoresis mobility. Their phenotype is difficult to determine during active disease due to low C4 levels as a result of increased consumption and complement activation. ${ }^{12}$ With molecular typing methods, determination of C4 homozygous and heterozygous deficiency states have become more accurate. ${ }^{15}$

The presence of C4A null allele (C4AQ0) with SLE is observed in Chinese, Caucasian and Japanese population; whereas, no association was found with C4B null allele. ${ }^{11}$ However, few studies reported no association of $\mathrm{C} 4 \mathrm{~A}$ null allele with $\mathrm{SLE}$, as in Malaysian, Spanish and French population. ${ }^{11,13}$

This study was planned with the objective to determine association of C4A null allele (C4AQ0) with systemic lupus erythematosus and its effect on clinical picture in terms of severity, organ involvement and laboratory findings in Pakistani population.

\section{METHODOLOGY}

This cross-sectional study was conducted from December 2018 to December 2019. Patients presenting at Immunology Department, AFIP who fulfilled 4 or more parameters of the American College of Rheumatology classification criteria (ACR 1997) of SLE, were included in this study. ${ }^{14}$ Patients without a clear diagnosis or those with other comorbid autoimmune diseases like diabetes or thyroid diseases were excluded from the study.

Permission from the Institutional Ethics Committee was sought prior to commencement of study. All the patients signed the informed consent before being enrolled. Sample size was calculated with Raosoft software; keeping margin of error $5 \%$, confidence level 95\%, and disease incidence 3.1 per 100,000. Sixtysix diagnosed patients of SLE and 40 age-matched control were enrolled. About $3 \mathrm{ml}$ venous blood samples in EDTA tubes were taken from all patients and controls. Genomic DNA was extracted from peripheral mononuclear cells using Flexi Gene DNA purification kit (Qiagen) as per manufacturer's instructions. Extracted DNA was suspended in ethanol at a final concentration of $100 \mathrm{ng} / \mu \mathrm{l}$. Purity of DNA was kept between 1.65 to 1.95, determined by Epoch microplate spectrophotometer (BioTek Instruments, USA) at 260/280nm. DNA from all samples were saved at $-20^{\circ} \mathrm{C}$ untilanalysis.

PCR master mix consisted of DNA Taq polymerase (thermofisher), dNTPs, $\mathrm{MgCl} 2$ (both from Thermofisher Scientific),
Taq buffer used was 10X with (NH4)2 S04; Thermo Fisher Scientific, USA. Internal control used was HLA-DRB1 locus-specific primers (Alpha DNA). About $15 \mu$ l of PCR master mix was put in each of the tubes and negative control tubes along with 3 microlitre of patient DNA. Forward and reverse primers $(1 \mu \mathrm{l})$ of customised C4A and C4B (Alpha DNA, Montreal QC, Canada) were added in 4 mini Eppendorf tubes, according to primers mix combination. PCR was performed on Multigene OptiMax Labnet international thermo-cycler. First denaturation was carried out at $94^{\circ} \mathrm{C}$ for 5 minutes. The next five cycles were performed at decreasing annealing temperature, one degree for every cycle from $68^{\circ} \mathrm{C}$ to $63^{\circ} \mathrm{C}$. Next 29 cycles were carried out at 30 seconds at $94^{\circ} \mathrm{C}, 1 \mathrm{~min}$ at $64^{\circ} \mathrm{C}$, and $1 \mathrm{~min}$ at $72^{\circ} \mathrm{C}$. Agarose gel $2 \%(\mathrm{w} / \mathrm{v})$ was prepared in $0.1 \mathrm{X}$ Tris/borate/EDTA buffer. Next, ethidium bromide and bromophenol dye were added to each PCR tube. The product was run on $2 \%$ agarose gel stained with ethidium bromide under ultraviolet light. The gel was finally examined in ultraviolet light and results documented. Primers used are shown in Table I.Other investigation results anti-Sjogren's syndrome antibody, anti-Smith antibody, anti Jo-1 and anti-Ribonucleoprotein antibody were also taken into account.

Creatinine clearance less than $80 \mathrm{ml} / \mathrm{min} / 1.73 \mathrm{~m}^{2}$ on more than two occasions was taken as diagnostic for renal impairment. Severity of renal damage was graded from 1 to 5 as per KDIGO criteria. Arthritis was diagnosed clinically in the presence of swelling, tenderness or effusion in two or more joints. Clinical characteristics and laboratory investigations of SLE were compared with $\mathrm{C} 4 \mathrm{~A}$ and $\mathrm{C} 4 \mathrm{~B}$ null alleles.

Statistical analysis was performed by using the SPSS 23.0. Frequency and percentages were calculated for the qualitative variable while mean and standard deviation were calculated for the quantitative variables. Fisher's Exact test was used to determine the association of C4A null allele with various clinical and laboratory parameters with $p$-value less than or equal to 0.05 as statistically significant.

\section{RESULTS}

Sixty-six patients of SLE were recruited in the study. Mean age of the study participants was $30.56( \pm 10.08)$ years. Sixty-four patients were females while only two patients were males, as shown in Table II. C4A was deficient in 7 (10.6\%) out of total 66 patients; and in 1 (2.5\%) out of 40 in the control group (Table II). Six (85.7\%) patients with C4A null allele had renal damage and all 7 patients (100\%) with C4A null allele had arthritis. Fisher's Exact test revealed significant association of $C 4 \mathrm{~A}$ null allele with arthritis and renal damage ( $P=0.039$ and 0.01 , respectively) as shown in Table III. Anti-Sjögren's-syndrome-related antigen A antibody (anti-SSA) was positive among 5 (71.4\%) patients with C4AQ0 ( $P=<0.001)$. C4B allele was deficient in $2(3 \%)$ out of 66 SLE patients and in none of the control group. No association of C4B null allele was found with clinical or laboratory parameters of SLE. Male patients had severe disease in terms of clinical manifestations and severity of renal impairment. 
Table I: Genotyping primers used. Sequence specific primers for PCR used in current study for detection of C4A \& C4B null allele.

\begin{tabular}{|c|c|c|c|c|}
\hline Gene & Primer & Sequence $(5-3)$ & Length of PCR & Reference \\
\hline C4A/C4AQ0 & $\begin{array}{l}\text { Aup } \\
\text { L3 } \\
\text { Ado } \\
\text { L4 }\end{array}$ & $\begin{array}{l}\text { GCATGCTCCTGTCTAACACTGGAC } \\
\text { TGCGGATCCAGCAGTITCGGAAG } \\
\text { AGGACCCCTGTCCAGTGTAGAC } \\
\text { ATAGGATCCTAAGGTCCCCTGGGCCT }\end{array}$ & $\begin{array}{l}\text { 377/null } \\
578 / \text { null }\end{array}$ & Barba et al. ${ }^{15}$ \\
\hline $\mathrm{C} 4 \mathrm{~B} / \mathrm{C} 4 \mathrm{BQ} 0$ & $\begin{array}{l}\text { Bup } \\
\text { L3 } \\
\text { Bdo } \\
\text { L4 }\end{array}$ & $\begin{array}{l}\text { TGCTCCTATGTATCACTGGAGAGA } \\
\text { TGCGGATCCAGCAGTTCGGAAG } \\
\text { AGGACCTCTCTCCAGTGATACAT } \\
\text { ATAGGATCCTAAGGTCCCCTGGGCCT }\end{array}$ & $\begin{array}{l}\text { 377/null } \\
578 / \text { null }\end{array}$ & Barba et al. ${ }^{15}$ \\
\hline
\end{tabular}

Table II: Demographic data and clinical presentation of patients included in the study.

\begin{tabular}{|c|c|c|}
\hline & Patients $(n=66)$ & Controls $(n=40)$ \\
\hline $\begin{array}{l}\text { Age (years): } \\
\text { Mean } \pm \text { SD } \\
\text { Range (min-max) }\end{array}$ & $\begin{array}{c}30.56( \pm 10.08) \\
10 \text { years }-61 \text { years }\end{array}$ & $\begin{array}{c}30.75( \pm 9.22) \\
10 \text { years }-60 \text { years }\end{array}$ \\
\hline $\begin{array}{l}\text { Gender: } \\
\text { Female } \\
\text { Male }\end{array}$ & $\begin{array}{l}64(97 \%) \\
02(3 \%)\end{array}$ & $\begin{array}{c}39(97.5 \%) \\
01(2.5 \%)\end{array}$ \\
\hline $\begin{array}{l}\text { C4 A Null Allele }{ }^{1} \text { : } \\
\text { Present } \\
\text { Absent }\end{array}$ & $\begin{array}{l}07(10.6 \%) \\
59(89.4 \%)\end{array}$ & $\begin{array}{c}1(2.5 \%) \\
39 \text { (97.5\%) }\end{array}$ \\
\hline $\begin{array}{l}\text { C4 B Null Allele }{ }^{2} \text { : } \\
\text { Present } \\
\text { Absent }\end{array}$ & $\begin{array}{l}02(3 \%) \\
64(97 \%)\end{array}$ & $\begin{array}{c}0 \\
40\end{array}$ \\
\hline $\begin{array}{l}\text { anti-dsDNA: } \\
\text { anti ENA antibodies } \\
\text { anti-SSA } \\
\text { anti-SSB } \\
\text { anti-Smith } \\
\text { anti-RNP } \\
\text { anti Jo-1 }\end{array}$ & $\begin{array}{c}64(97 \%) \\
07(10.6 \%) \\
01(1.5 \%) \\
02(3.0 \%) \\
02(3.0 \%) \\
00(0 \%)\end{array}$ & \\
\hline $\begin{array}{l}\text { Clinical features: } \\
\text { Rash } \\
\text { Photosensitivity } \\
\text { Oral ulcer } \\
\text { Arthritis } \\
\text { Renal damage } \\
\text { Serositis } \\
\text { Hematologic involvement }\end{array}$ & $\begin{array}{l}36(54.5 \%) \\
22(33.3 \%) \\
20(30.3 \%) \\
41(62.1 \%) \\
25(37.9 \%) \\
11(16.7 \%) \\
14(21.2 \%) \\
\end{array}$ & \\
\hline \multicolumn{3}{|c|}{$\begin{array}{l}\text { C4 A: complement protein } 4 A, C 4 B \text { : complement protein } 4 B, E N A: \text { extractable } \\
\text { nuclear antigens, SSA: Sjögren's-syndrome-related antigen A, SSB: Sjögren's- } \\
\text { syndrome-related antigen B, RNP: Ribonucleoprotein. }{ }^{1} C 4 A \text { null allele was present in } \\
7 \text { of } 66 \text { SLE patients and } 1 \text { of } 40 \text { controls. }{ }^{2} C 4 B \text { null allele was present in } 2 \text { of } 66 \text { SLE } \\
\text { patients and none of the control population. }\end{array}$} \\
\hline
\end{tabular}

\section{DISCUSSION}

This study was planned with the objective to determine association of $\mathrm{C} 4$ null alleles (C4AO and $\mathrm{C} 4 \mathrm{~B} 0$ ) with systemic lupus erythematosus in the local population and its impact on clinical presentation and laboratory findings. An increased frequency of C4A null allele was found in SLE compared to the control group $(10.6 \%$ vs $02.5 \%)$ and increased risk of arthritis and renal damage in these patients.

In this study, seven out of the 66 patients (10.6\%) had homozygous C4A deficient alleles. This is in accordance with the international data which reports $10-15 \%$ SLE patients being homozygous deficient. ${ }^{16}$ Petri et al. observed significant increase in C4A null alleles among SLE patients versus controls in African-American (61\% vs 13\%) and European-American population ( $43 \%$ vs $25 \%$ ). ${ }^{17}$ In a study of French-Canadian and non-French-Canadian lupus patients, a significant association of C4AQ0 in SLE patients in nonFrench-Canadian group was seen. ${ }^{18}$ In the Asian population, incidence of C4AQ0 is less relative to western data and more comparable to the results of this study. Man et al. reported $12.5 \%$ incidence of C4AQ0 in SLE patients and $1.1 \%$ in the control group in South-West Chinese population. ${ }^{19}$ However, Spanish, Greek and Malaysian studies failed to detect a significant association of lupus patients with C4A null alleles. ${ }^{13,20,21}$

A significant association of C4AQ0 with arthritis and renal damage was found. All patients with C4A deficiency had arthritis and $85.7 \%$ ( 6 out of 7 ) had renal impairment; $p=0.039$ and 0.01 , respectively (Table III). Similar results are reported by Clemenceau et al. who found increased risk of renal involvement, in 9 out of 11 patients with C4AQ0 ${ }^{22}$ However, no such association was found by Schur et al. in USA and Kramer et al. in Hungry. ${ }^{23,24}$ This can be due to clinical heterogeneity and ethnic differences in populations.

Arthritis was significantly more among the SLE patients with C4AQ0 compared to the patients without C4A deficiency, $100 \%$ vs $57.6 \%$ (Table III). Tsang et al. also reported increased severity of arthritis in SLE patients with C4A null allele. ${ }^{25}$ Juptner et al. observed early onset and severe disease in SLE patients with C4AQ0 in German population, though no such association with age was observed in this study. ${ }^{10}$ This early disease onset and increased severity is due to C4A deficiency, that results in impaired clearance of immune complexes which get deposited at various locations like kidney, synovium and serosa leading to inflammation and damage. ${ }^{16,17}$

In this study, 5 out of 7 patients (71.4\%) with C4A null allele showed antibody to SSA (Sjögren's-syndrome-related antigen $A$ ); $p<0.001$, which is in agreement with Naves et al. and Revellive et al. who also demonstrated this association. ${ }^{20,21}$ 
Table III: Fisher's Exact test for relationship of various clinical and laboratory findings with the presence of C4A null alleles among the SLE patients This table shows association of C4A null allele with clinical features \& diagnostic tests in SLE patients.

\begin{tabular}{|c|c|c|c|c|c|}
\hline \multirow{2}{*}{ Characteristics } & \multirow{2}{*}{ Status } & \multicolumn{2}{|c|}{ C4A } & \multirow{2}{*}{ Total } & \multirow{2}{*}{ p-value } \\
\hline & & Present $n=59$ & Absent $n=7$ & & \\
\hline \multirow{2}{*}{ Age } & $<25$ years & $21(35.6 \%)$ & $2(28.6 \%)$ & 23 & \multirow{2}{*}{$>0.999$} \\
\hline & $>25$ years & 38 (64.4\%) & $5(71.4 \%)$ & 43 & \\
\hline \multirow{2}{*}{ Malar rash } & Present & 32 (54.2\%) & $4(57.1 \%)$ & 36 & \multirow{2}{*}{$>0.999$} \\
\hline & Absent & $27(45.8 \%)$ & $3(42.9 \%)$ & 30 & \\
\hline \multirow{2}{*}{ Oral ulcer } & Present & $17(28.8 \%)$ & $3(42.9 \%)$ & 20 & \multirow{2}{*}{0.425} \\
\hline & Absent & $42(71.2 \%)$ & $4(57.1 \%)$ & 46 & \\
\hline \multirow{2}{*}{ Arthritis } & Present & $34(57.6 \%)$ & $7(100 \%)$ & 41 & \multirow{2}{*}{$0.039^{*}$} \\
\hline & Absent & 25 (42.4\%) & 0 & 25 & \\
\hline \multirow{2}{*}{ Renal damage } & Present & $19(32.2 \%)$ & $6(85.7 \%)$ & 25 & \multirow{2}{*}{$0.01^{*}$} \\
\hline & Absent & $40(67.8 \%)$ & $1(14.3 \%)$ & 41 & \\
\hline \multirow{2}{*}{ Anti-dsDNA } & Present & $58(98.3 \%)$ & $6(85.7 \%)$ & 64 & \multirow{2}{*}{0.202} \\
\hline & Absent & $1(1.7 \%)$ & $1(14.3 \%)$ & 2 & \\
\hline \multirow{2}{*}{ Anti SSA } & Present & $2(3.4 \%)$ & $5(71.4 \%)$ & 7 & \multirow{2}{*}{$<0.001^{*}$} \\
\hline & Absent & $57(96.6 \%)$ & $2(28.6 \%)$ & 59 & \\
\hline \multirow{2}{*}{ Anti Smith } & Present & $1(1.7 \%)$ & $1(14.3 \%)$ & 2 & \multirow{2}{*}{0.202} \\
\hline & Absent & $58(98.3 \%)$ & $6(85.7 \%)$ & 64 & \\
\hline \multirow{2}{*}{ Anti Jo-1 } & Present & 0 & 0 & 0 & \multirow{2}{*}{$* *$} \\
\hline & Absent & 59 & 7 & 66 & \\
\hline \multirow{2}{*}{ Anti RNP } & Present & $2(3.4 \%)$ & $0(0 \%)$ & 2 & \multirow{2}{*}{$>0.999$} \\
\hline & Absent & 57 (96.6\%) & $7(100 \%)$ & 64 & \\
\hline
\end{tabular}

In our study, no association was found between C4BQ0 and SLE which was in general agreement with other studies. ${ }^{11,23}$ Although C4BQ0 played an important part in SLE susceptibility in Spanish population (OR 6.0, $p<0.001) .{ }^{21}$ This could be due to difference in ethnicity and haplotype tested. Indeed, majority of studies showed no increase in C4BQO allele in Caucasoid, Asian and African- American population. ${ }^{11,13,18}$

Most of the patients in this study were females, only two males. This is consistent with the historical data. ${ }^{18}$ It was also observed that manifestations of SLE were more severe in male patients as compared to female patients.

In the control group, only one patient had C4A null allele and none had C4B null allele (Table II). Different studies have shown a variable incidence of C4A null allele in control groups that ranged from $13 \%$ in African-American, $25 \%$ in European-American; whereas, $1.1 \%$ in Chinese population. This difference in expression can be due to difference in ethnicity and genetic make-up., ${ }^{6,11,18,20}$

There are various limitations of this present study. Firstly, the sample size is small, as it is often difficult to obtain a large number of SLE patients in a single hospital. Secondly, SLE is a complex disease. Due to the dynamic nature of disease, there may be many different sets of genetic and biologic players causing pathogenesis of SLE and resultant clinical manifestations, which may not be addressed in this study. Thirdly, there is genetic heterogeneity and various ethnic factors that have impact upon development and progression of SLE disease. Pakistani population is diverse and has many different ethnic groups distributed all over the country. The study centre is located in the northern part of the country; therefore, the studied population is not representative of all Pakistani population. A large multicenter prospective study can generate generalised results for our population and we could set our own guidelines for the complement testing among SLE patients.

This study gives an insight into the pattern of C4A deficiency among SLE patients and its impact on clinical presentation in Pakistani population. Knowledge of C4A status at diagnosis in SLE patients will help the physician predict disease course. Close monitoring of risk organs and early intervention will reduce morbidity and improve long term outcome.

\section{CONCLUSION}

Homozygous absence of C4A alleles is seen in $10.6 \%$ of SLE patients in Pakistani population. It marks increased risk of arthritis, renal impairment and detection of anti SSA antibodies. Testing for C4A null allele should be included in initial testing of SLE to predict disease course and better long-term management.

\section{ETHICAL APPROVAL:}

Approval from Institutional Review Board of Armed Forces Institute of Pathology was taken prior to commencement of this study. 


\section{PATIENTS' CONSENT:}

Informed consents for participation in the study and publication of results were taken from all the patients at the time of enrollment.

\section{CONFLICT OF INTEREST:}

The authors declared no conflict of interest.

\section{AUTHORS' CONTRIBUTION:}

AAA: Design of the study, acquisition, analysis, and interpretation of data, preparation of manuscript and final draft.

HNT: Conception and design of study, monitoring, correction and final approval of draft.

DA: Conception and design of study, final approval of draft. MF: Analysis and interpretation of data, preparation of draft.

\section{REFERENCES}

1. Andreoli L, Bertsias GK, Agmon-Levin N, Brown S, Cervera R, Chalumeau NC, et al. EULAR recommendations for women's health and the management of family planning, assisted reproduction, pregnancy and menopause in patients with systemic lupus erythematosus and/or antiphospholipid syndrome. Ann Rheum Dis 2017; 76(3):476-85. doi:10.1136/annrheumdis-2016-209770.

2. Itikyala S, Pattanaik D, Raza S. Systemic lupus erythematosus (SLE) and antineutrophil cytoplasmic antibody-associated vasculitis (AAV) overlap syndrome: Case report and review of the literature. Case Rep Rheumatol 2019; 2019:5013904. doi:10.1155/2019/5013904.

3. Stojan G, Petri M. Epidemiology of systemic lupus erythematosus: An update. CurrOpinRheumatol 2018; 30(2):144-150. doi:10.1097/BOR.0000000000000480.

4. Osio-Salido E, Manapat-Reyes H. Epidemiology of systemic lupus erythematosus in Asia. Lupus 2010; 19(12):1365-73. doi: 10.1177/0961203310374305.

5. Yen EY, Shaheen M, Woo JMP. 46-year trends in systemic lupus erythematosus mortality in the United States, 1968 to 2013: A nationwide population-based study. Ann Intern Med 2017; 167(11):777-85. doi:10.7326/M17-0102.

6. Rabbani MA, Habib HB, Islam M, Ahmad B, Majid S, Saeed $W$, et al. Survival analysis and prognostic indicators of systemic lupus erythematosus in Pakistani patients. Lupus 2009; 18(9):848-55. doi: 10.1177/0961203309103410.

7. Liesmaa I, Paakkanen R, Järvinen A, Valtonen V, Lokki ML. Clinical features of patients with homozygous complement C4A or C4B deficiency. PloS One 2018; 13(6):e0199305. doi: 10.1371/journal.pone.0199305.

8. Macedo AC, Isaac L. Systemic lupus erythematosus and deficiencies of early components of the complement classical pathway. Frontiers in immunology 2016; 7:55. doi: 10.3389/fimmu.2016.00055.

9. Chai HC, Phipps ME, Chua KH. Genetic risk factors of systemic lupus erythematosus in the Malaysian population: A minireview. Clin Dev Immunol 2011; 2012:963730. doi: 10.1155/2012/963730.

10. Jüptner M, Flachsbart F, Caliebe A, Lieb W, Schreiber S, Zeuner R, et al. Low copy numbers of complement $C 4$ and homozygous deficiency of C4A may predispose to severe disease and earlier disease onset in patients with systemic lupus erythematosus. Lupus 2018; 27(4):600-9. doi: 10.1177/0961203317735187.

11. Dunckley H, Gatenby PA, Hawkins B, Naito S, Serjeantson SW. Deficiency of C4A is a genetic determinant of systemic lupus erythematosus in three ethnic groups. J Immunogenet 1987; 14(4-5):209-18. doi: 10.1111/j.1744-313x.1987.tb00383.x.

12. Sandhu V, Quan M. SLE and serum complement: Causative, concomitant or coincidental. Open Rheumatology J 2018; 12:171. doi: 10.2174/1874312901812010171.

13. Puah SM, Lian LH, Chew CH, Chua KH, Tan SY. A study of association of the complement $\mathrm{C} 4$ mutations with systemic lupus erythematosus in the Malaysian population. Lupus 2007; 16(9):750-4. doi: 10.1177/0961203307079454.

14. Tiao J, Feng R, Carr K, Okawa J, Werth VP. Using the American college of rheumatology (ACR) and systemic lupus international collaborating clinics (SLICC) criteria to determine the diagnosis of systemic lupus erythematosus (SLE) in patients with subacute cutaneous lupus erythematosus (SCLE). J Am Acad Dermatol 2016; 74(5):862-9. doi:10.1016/ j.jaad.2015.12.029

15. Barba GMR, Braun-Heimer L, Rittner C, Schneider PM. A new PCR-based typing of the Rodgers and Chido antigenic determinants of the fourth component of human complement. Eur J Immunogenet 1994; 21(5):325-39. doi: 10.1111/ j.1744-313x.1994.tb00203.x.

16. Pereira KM, Faria $A G$, Liphaus $B L$, Jesus $A A$, Silva $C A$, Carneiro-Sampaio M, et al. Low C4, C4A and C4B gene copy numbers are stronger risk factors for juvenile-onset than for adult onset systemic lupus erythematosus. Rheumatology 2016; 55(5):869-73. doi: 10.1093/rheumatology/kev436.

17. Petri M, Watson R, Winkelstein JA, McLean RH. Clinical expression of systemic lupus erythematosus in patients with C4A deficiency. Medicine 1993; 72(4):236-44. doi: 10.1097/ 00005792-199307000-00003.

18. Goldstein R, Sengar DP. Comparative studies of the major histocompatibility complex in French Canadian and non-French Canadian Caucasians with systemic lupus erythematosus. Arthritis Rheum 1993; 36(8):1121-7. doi.org/10.1002/art.1780360813.

19. Man XY, Luo HR, Li XP, Yao YG, Mao CZ, Zhang YP. Polymerase chain reaction based $C 4 A Q 0$ and $C 4 B Q 0$ genotyping: Association with systemic lupus erythematosus in southwest Han Chinese. Ann Rheum Dis 2003; 62(1):71-3. doi: 10.1136/ard.62.1.71.

20. Reveille JD, Moulds JM, Ahn C, Friedman AW, Baethge B, Roseman J, et al. Systemic lupus erythematosus in three ethnic groups: I. The effects of HLA class II, C4, and CR1 alleles, socioeconomic factors, and ethnicity at disease onset. Arthritis Rheumatism 1998; 41(7):1161-72. doi: 10.1002/1529-0131(199807)41:7<1161::AID-ART4>3.0.$\mathrm{CO} ; 2-\mathrm{K}$.

21. Naves M, Hajeer AH, Teh LS, Davies EJ, Ordi-Ros J, PerezPemen $\mathrm{P}$, et al. Complement C4B null allele status confers risk for systemic lupus erythematosus in a Spanish population. Eur J Immunogenet 1998; 25(4):317-20. doi: 10.1046/j.1365-2370.1998.00110.x.

22. Clemenceau S, Castellano F, de Oca MM, Kaplan C, Danon F, 
Levy M. C4 null alleles in childhood onset systemic lupus erythematosus. Pediatr Nephrol 1990; 4(3):207-12. doi: 10.1007/BF00857655.

23. Schur PH, Marcus D, Awdeh Z, Yunis EJ, Alper CA. Extended $\mathrm{MHC}$ haplotypes and complement genes in systemic lupuserythematosus (SLE). Clin Res 1988; 36(3):pp. A600-A600.

24. Kramer J, Ftist G, Stenszky V, Szegedi G, Gergely P. Is there any correlation between the presence of C4AQ0 and SLE. Complement 1988; 5:209.

25. Tsang-A-Sjoe MW, Bultink IE, Korswagen LA, Van Der Horst A, Rensink I, de Boer $M$, et al. Comprehensive approach to study complement $\mathrm{C} 4$ in systemic lupus erythematosus: Gene polymorphisms, protein levels and functional activity. Mol Immunol 2017; 92:125-31. doi: 10.1016/j.molimm. 2017.10.004. 